\title{
Value of systolic time intervals in assessing severity of congenital aortic stenosis in children ${ }^{1}$
}

\author{
Rudolf J. Moene, Gerrit A. Mook, Kuno Kruizinga, Arend Bergstra, and Klaas K. Bossina \\ From the Departments of Pediatric Cardiology and Chemical Physiology, University of Groningen, and the \\ Department of Pediatric Cardiology, Free University, Amsterdam, The Netherlands
}

Simultaneous recordings have been made of electrocardiogram, phonocardiogram, carotid pulse tracing, left ventricular pressure, and aortic pressure in 27 children with aortic valve stenosis and 3 children with membranous subaortic stenosis. Peak systolic pressure difference ranged from Io to IIO $\mathrm{mmHg}$ (I.3 to I4.6 kPa). None of the patients had congestive heart failure and cardiac output was in the normal range in all. Total electromechanical systole, left ventricular ejection time, and pre-ejection time were corrected for heart rate, age, and sex. Mild stenosis (peak systolic pressure difference $\leqslant 50 \mathrm{mmHg}(6.7 \mathrm{kPa})$ ) was present in $\mathrm{I} 8$, severe stenosis (peak systolic pressure difference $>50 \mathrm{mmHg}$ ) in 12 patients. The externally measured pre-ejection time and ejection time proved to be nearly equal to the corresponding intervals measured internally; from these data it is concluded that pre-ejection time and ejection time in children with aortic stenosis can be measured reliably by non-invasive methods. Mean values for corrected total electromechanical systole and ejection time were prolonged, but the corrected pre-ejection time did not differ from the normal value. When corrected time intervals were plotted against severity of the aortic stenosis as expressed by the peak systolic pressure difference or the aortic valve orifice index, a wide scatter was found. It is concluded that a normal ejection time is strong evidence against a peak systolic pressure difference of more than $50 \mathrm{mmHg}(6.7 \mathrm{kPa})$ or an aortic valve orifice index less than $0.70 \mathrm{~cm}^{2}$ per $\mathrm{m}^{2} B S A$. A prolonged ejection time, however, may occur in mild as well as in severe stenosis. Total electromechanical systole and pre-ejection time have no value in predicting the severity of aortic stenosis in children.

Most of the data from numerous studies, concerning the relation between systolic time intervals and the severity of aortic stenosis, refer to adult patients. No groups consisting exclusively of children have been investigated. When aortic valve stenosis is complicated by ventricular decompensation, which occurs far more often in adults than in children, the initially shortened pre-ejection time and prolonged ejection time may become normal or less abnormal than in compensated aortic stenosis (Bonner and Tavel, 1972; Weissler, Lewis, and Leighton, 1972). This may be one of the causes of the poor correlation between systolic time intervals and the degree of stenosis as found in adults (Benchimol, Dimond, and Shen, 1960; Braunwald et al., 1963; Epstein and Coulshed, 1964; Sherman et al., I97I; Ibrahim et al., 1973). Moreover, variations in cardiac Received 19 March 1975.

I This work was supported by a grant from the Netherlands Organization for the Advancement of Pure Research (Z.W.O.), received through the Foundation for Basic Medical Research (Fungo). function, either spontaneous or caused by the catheterization procedure, may affect the relation between the internally measured degree of aortic stenosis and the externally measured systolic time intervals, if these measurements are not performed simultaneously. To date, to our knowledge, the value of systolic time intervals in predicting the severity of the aortic stenosis in children has not been critically investigated by simultaneous recordings using invasive and non-invasive methods.

The present study was undertaken to assess the value of systolic time intervals obtained by noninvasive methods in predicting the severity of congenital valvar or discrete subvalvar aortic stenosis in a group of 30 children without clinical signs of congestive heart failure. Simultaneous recordings were obtained by invasive and noninvasive methods.

\section{Patients and methods}

In all 30 patients (Table 1 ) a grade 3 to 4 ejection type murmur was present with maximum intensity at the 


\section{TABLE I Clinical data of the 30 patients studied}

\begin{tabular}{ll} 
Age (yr) & $\begin{array}{l}7-16 \text { (mean II) } \\
\text { Sex }\end{array}$ \\
Site of stenosis & Valvar 97 ; discrete subvalvar 3 \\
Associated anomalies & $\begin{array}{l}\text { Slight aortic valve regurgitation 4 } \\
\text { Significant aortic valve regurgitation I } \\
\text { Secundum atrial septal defect I (left- } \\
\text { to-right shunt 20\%) } \\
\text { Normal I7 }\end{array}$ \\
Electrocardiogram & $\begin{array}{l}\text { Left ventricular hypertrophy by } \\
\text { voltage criteria 5 } \\
\text { Left ventricular hypertrophy with } \\
\text { strain pattern } 8\end{array}$ \\
\hline
\end{tabular}

second right intercostal space, well transmitted to the carotid arteries and accompanied by a systolic thrill, signifying the presence of aortic stenosis. The presence of this murmur was observed before the age of 5 , and no patient had a history suggestive of acute rheumatic fever. An aortic ejection click was present at the lower sternal border in the patients with valvar aortic stenosis and absent in the 3 patients who, at cardiac catheterization, were found to have discrete subvalvar aortic stenosis.

After right heart catheterization all patients underwent diagnostic left heart catheterization with simultaneous recording of external pulse tracings, phonocardiogram, and electrocardiogram. The first 5 patients were sedated with pethidine and promethazine, the dose being individually chosen. Restlessness in some children towards the end of the catheterization procedure, however, made it necessary to terminate the procedure prematurely. For this reason light general anaesthesia was used in the other patients. After premedication with 0.25 to $0.50 \mathrm{mg}$ atropine 45 minutes previously, anaesthesia was induced by intravenous injection of 100 to $150 \mathrm{mg}$ thiopentone sodium. After the intravenous administration of 50 to $75 \mathrm{mg}$ suxamethonium chloride the patient was intubated. Anaesthesia was maintained with a mixture of nitrous oxide (6 $1 / \mathrm{min})$ and oxygen $(3 \mathrm{l} / \mathrm{min})$, from time to time supplemented with small amounts of intravenously administered pethidine. This kind of anaesthesia allows the patient to breath spontaneously. Since the general anaesthesia was kept light, local anaesthesia with I per cent lignocaine was used at the site of the venous and arterial cut-down.

\section{Invasive methods}

After exposure of the right antecubital vein, the tip of an F6 or $\mathrm{F}_{7} \mathrm{Pt}$ electrode catheter was positioned in the pulmonary artery. This catheter was connected to a Statham $\mathrm{P}_{23} \mathrm{Db}$ pressure transducer, set at zero level $5 \mathrm{~cm}$ below the sternal angle. The same catheter was also used for dye injection. A second catheter (Gensini F6 or F7) was introduced into one of the femoral arteries using the Seldinger technique, and the tip advanced into the ascending aorta. The left ventricle was entered retrogradely by way of the right brachial artery using a Gensini F6 catheter in 17 patients and an $F_{5}$ cathetertip manometer (Millar PC-350) in 13 patients. The fluidfilled aortic and left ventricular catheters were connected to a Statham $\mathrm{P}_{23} \mathrm{H}$ differential pressure transducer set at zero level $5 \mathrm{~cm}$ below the sternal angle. When the catheter tip was used for left ventricular pressure measurements, the aortic catheter was connected to a Statham $\mathrm{P}_{23} \mathrm{Db}$ transducer. The zero level for the left ventricular pressure measurement using the catheter tip manometer was adjusted to that of the aortic catheter. Dye dilution curves were obtained by injecting $2.5 \mathrm{mg}$ indocyanine green into the pulmonary artery and sampling from the aorta. For that purpose the aortic catheter was connected to a suction device and a linear reflection densitometer (Ten Hoor and Mook, 1969). At the end of the catheterization cineangiocardiograms were made with contrast injection into the left ventricle and the aortic root. The left ventricular end-diastolic pressure was measured from high gain pressure curves either as the minimum pressure immediately after the ' $a$ ' wave or as the pressure at the moment of the beginning of the steep pressure rise. The average of 10 endexpiratory measurements was used. The left ventricularaortic peak systolic pressure difference was measured from simultaneously recorded pressure curves. The mean systolic pressure difference was obtained by planimetric integration, using the average of 5 consecutive beats. Cardiac output was calculated from the dye dilution curves using the Stewart-Hamilton equation. Stroke volume was obtained by dividing cardiac output by heart rate. The aortic valve orifice was calculated using the formulae of Gorlin and Gorlin (I95I). Cardiac output, stroke volume, and aortic valve area were divided by body surface area to obtain cardiac index, stroke index, and aortic valve orifice index. The left ventricular ejection time $t_{e}\left(P_{a o}\right)$ was measured from the beginning of the upstroke of the aortic pressure curve to the trough of the incisura. The pre-ejection time $t_{p e}(P)$ was obtained by measuring the interval between the beginning of the $Q$ wave and the point where the upstroke of the left ventricular pressure tracing from the catheter tip manometer reached the diastolic aortic pressure (Fig. I).

\section{Non-invasive methods}

For the electrocardiogram the lead with the earliest and clearest $Q$ wave was taken. The phonocardiogram was recorded with a crystal microphone (Hewlett-Packard I40I I A) using either a roo or $200 \mathrm{~Hz}$ cut-off frequency. The microphone was placed over the upper part of the praecordium in a position optimal for recording the initial high frequency vibrations of the first and second heart sound. The carotid artery pulse tracing was recorded with a funnel-shaped pickup connected to a pressure transducer (Statham $\mathrm{P}_{23} \mathrm{Db}$ ) by a steel tube (length $4 \mathrm{~cm}$, internal diameter $4 \mathrm{~mm}$ ). The funnel was placed over the carotid artery and the vent of the transducer then closed for recording the pulse. Respiration was recorded by a thermistor placed in front of one of the nostrils or inserted in the airway tube when general anaesthesia was employed. To study the possible effect of the catheterization procedure on the systolic time intervals, simultaneous recordings of electrocardiogram, phonocardiogram, carotid pulse tracing, and respiration were made less than 48 hours before the catheterization 


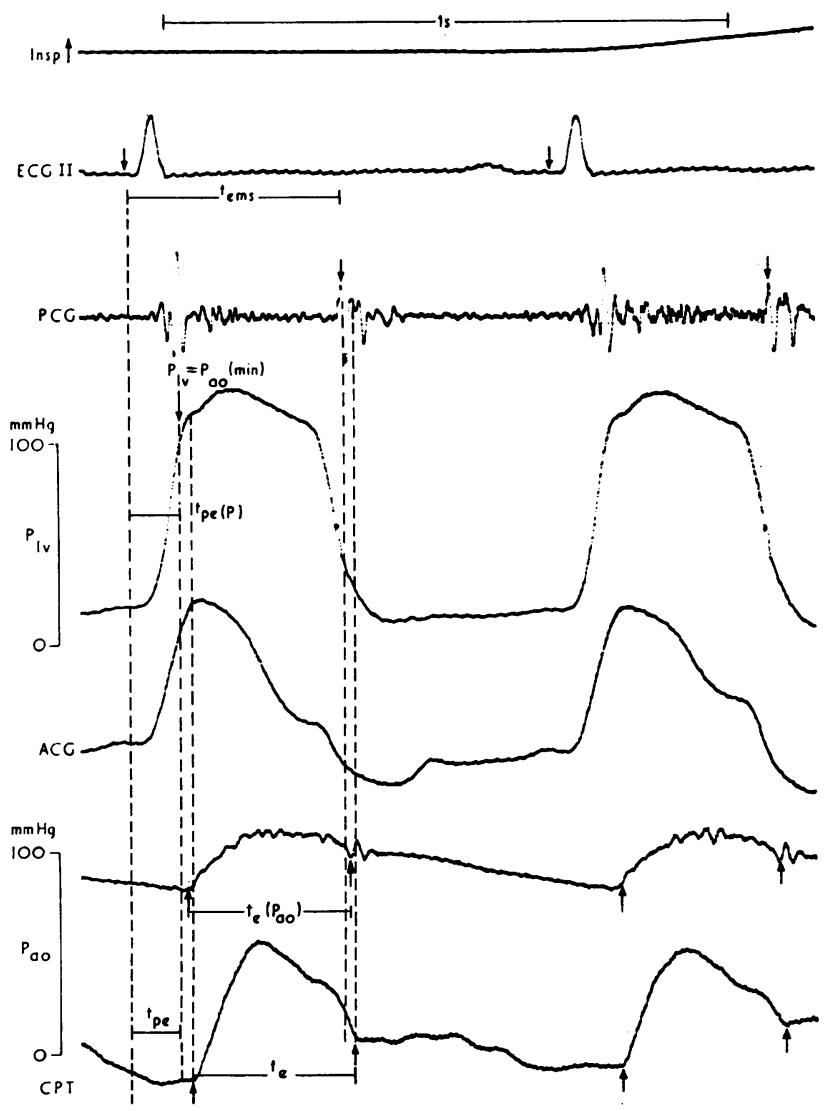

FIG. I Simultaneous recordings of respiration (insp. $\uparrow$ ), electrocardiogram (ECG II), phonocardiogram (PCG), left ventricular pressure $\left(P_{l v}\right)$, aortic pressure $\left(P_{a 0}\right)$, and carotid artery pulse tracing $(C P T)$ in a child with minimal aortic stenosis (peak systolic pressure difference $=$ Io $\mathrm{mmHg}(\mathrm{I} .3 \mathrm{kPa})$ ), illustrating the measurement of systolic time intervals. The symbols denote the time intervals and are explained in the text. The intervals between each pair of dashed lines represent the carotid pulse transmission time. The apex cardiogram (ACG) was used to determine the electromechanical delay and the isovolumic contraction time, the results of which have been published elsewhere (Moene, 1974).

in 20 patients. All signals were recorded on an Elema EMTr60 multichannel recorder (paperspeed $100 \mathrm{~mm} \mathrm{~s}$ ) and stored on magnetic tape (Ampex FR-r300 A).

The following systolic time intervals were externally determined (Fig. I). The total electromechanical systole $t_{e m s}$ was measured from the beginning of the $Q$ wave of the electrocardiogram to the first high frequency vibrations of the aortic component of the second heart sound. The left ventricular ejection time $t_{e}$ was measured from the beginning of the upstroke of the carotid artery pulse tracing to the trough of the incisura. The preejection time $t_{p e}$ was obtained by subtracting the ejection time from the total electromechanical systole. In addition the ratio of pre-ejection time to ejection time was calculated. All time intervals were measured in 5 to Io consecutive cardiac cycles and then averaged. The beginning and the end of a series of consecutive readings were selected so as to fall within one and the same respiratory cycle. Measurements were made to the nearest $5 \mathrm{~ms}$. The time intervals were corrected for heart rate, age, and sex, using the method of Moene (1974), based on regression equations published by Golde and Burstin (1970) and Weissler, Harris, and Schoenfeld (1968). According to this method the normal values are as follows: $t_{e m}=378 \pm \mathrm{I} 4 \mathrm{~ms} ; t_{e}=277 \pm \mathrm{I} 0 \mathrm{~ms} ; t_{p e}=99 \pm$ I3 ms.

\section{Results}

Table 2 presents heart rate, total electromechanical systole, left ventricular ejection time, and preejection time as measured externally less than 
TABLE 2 Total electromechanical systole, ejection time, pre-ejection time, and heart rate measured externally within 49 hours before cardiac catheterization and during cardiac catheterization

\begin{tabular}{|c|c|c|c|c|c|c|c|c|c|c|c|c|}
\hline \multirow[t]{2}{*}{ Case No. } & \multicolumn{3}{|c|}{ Heart rate/min } & \multicolumn{3}{|c|}{$\begin{array}{l}\text { Total electromechanical } \\
\text { systole (ms) }\end{array}$} & \multicolumn{2}{|c|}{$\begin{array}{l}\text { Ejection time } \\
\text { (ms) }\end{array}$} & \multirow[b]{2}{*}{$\Delta$} & \multicolumn{3}{|c|}{$\begin{array}{l}\text { Pre-ejection time } \\
\text { (ms) }\end{array}$} \\
\hline & $\boldsymbol{B}$ & $D$ & $\Delta$ & $B$ & $D$ & $\Delta$ & $B$ & $D$ & & $B$ & $D$ & $\Delta$ \\
\hline $\mathbf{I}$ & 105 & II5 & + 10 & 4I 4 & 429 & +15 & 287 & 296 & +9 & 126 & 127 & $+\mathrm{r}$ \\
\hline 2 & 115 & IOI & -14 & 416 & 392 & -24 & $3 I I$ & 302 & -9 & 103 & 89 & -14 \\
\hline 3 & 90 & 80 & -10 & 377 & 385 & +8 & 372 & 300 & -2 & 85 & 92 & +7 \\
\hline 5 & III & 84 & -27 & 393 & 388 & -5 & 292 & 299 & +7 & 94 & 93 & -1 \\
\hline 7 & 117 & 107 & -10 & 385 & 382 & -3 & 297 & 283 & -14 & 87 & 98 & +11 \\
\hline 8 & 86 & 100 & +14 & 378 & 408 & +30 & 292 & 319 & +27 & 86 & 89 & +3 \\
\hline 9 & 90 & 113 & +23 & 405 & 437 & +32 & 293 & 314 & +21 & I IO & 121 & +11 \\
\hline Ió & 65 & 77 & +12 & 409 & 416 & +7 & 330 & 326 & -4 & 77 & 88 & +11 \\
\hline II & 77 & 90 & +13 & 395 & 406 & + I I & 300 & 298 & -2 & 94 & 106 & +12 \\
\hline 12 & 82 & 74 & -8 & 420 & 444 & +24 & 305 & 319 & +14 & 103 & I 10 & +7 \\
\hline 16 & 89 & III & +22 & 409 & 425 & +16 & 290 & 312 & +22 & 124 & 126 & +2 \\
\hline 17 & 70 & 79 & +9 & 401 & 401 & +0 & 327 & 298 & -29 & 76 & 108 & +32 \\
\hline 18 & 90 & 75 & -15 & 361 & 389 & +28 & 267 & 291 & +24 & 102 & 107 & +5 \\
\hline 19 & 90 & I10 & +20 & 387 & 402 & +15 & 289 & 276 & -13 & 97 & 124 & +27 \\
\hline 23 & 75 & 86 & $+I I$ & 420 & 428 & +8 & 309 & 326 & +27 & IOI & 95 & -6 \\
\hline 24 & 97 & 97 & to & 410 & 425 & +15 & 314 & 339 & +25 & 95 & 85 & -10 \\
\hline 25 & 90 & 97 & +7 & 406 & 450 & +44 & 301 & 311 & +10 & 103 & 141 & +38 \\
\hline 28 & 90 & 93 & +3 & 391 & 429 & +38 & 309 & 305 & -4 & 80 & 124 & +44 \\
\hline 29 & 75 & 72 & -3 & 359 & 395 & +36 & 291 & 293 & +2 & 74 & 107 & +33 \\
\hline 30 & 90 & II4 & +24 & 427 & 465 & +38 & 322 & 342 & +22 & 103 & 122 & +19 \\
\hline Mean & 89 & 93 & & 398 & 414 & & 301 & 307 & & 96 & 107 & \\
\hline SD & 14 & 24 & & 19 & 23 & & I5 & 17 & & 14 & 16 & \\
\hline$n$ & 20 & 20 & & 20 & 20 & & 20 & 20 & & 20 & 20 & \\
\hline
\end{tabular}

$\mathrm{B}=$ before cardiac catheterization $; \mathrm{D}=$ during cardiac catheterization $; \nu=$ difference in value before and during cardiac catheterization.

$\mathrm{SD}=$ standard deviation; $n=$ number of measurements. The time intervals have been corrected for heart rate, age, and sex.

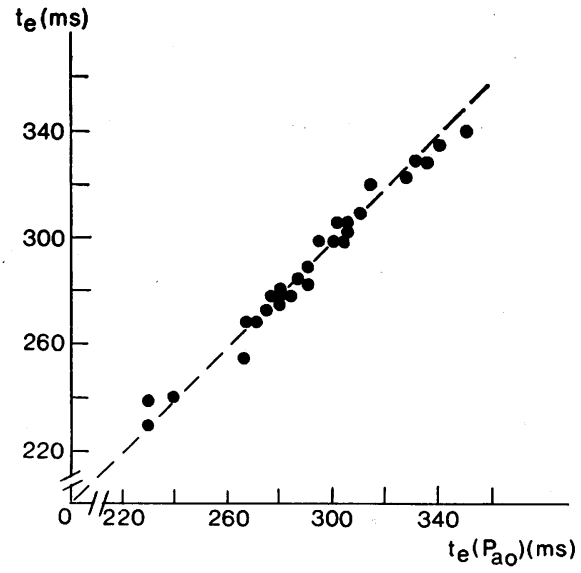

FIG. 2 Correlation of the ejection time as measured from the carotid pulse tracing $\left(t_{e}\right)$ with the ejection time as measured from the aortic pressure tracing $\left(t_{e}\left(P_{a 0}\right)\right) ; r=+0.99$. The interrupted line is the bisector of the coordinate system. 
TABLE 3 Total electromechanical systole, left ventricular ejection time, and pre-ejection time as measured during cardiac catheterization

\begin{tabular}{|c|c|c|c|c|c|c|c|c|c|c|}
\hline Case No. & $\begin{array}{l}\text { Heart rate } \\
\text { (beats/min) }\end{array}$ & $\begin{array}{l}t_{e m s} \\
(m s)\end{array}$ & $\begin{array}{c}t_{e m s}^{*} \\
(m s)\end{array}$ & $\begin{array}{l}t_{e} \\
(m s)\end{array}$ & $\begin{array}{l}t_{\epsilon}\left(P_{a 0}\right) \\
(m s)\end{array}$ & $\begin{array}{l}t_{e}^{*} \\
(m s)\end{array}$ & $\begin{array}{l}t_{p e} \\
(m s)\end{array}$ & $\begin{array}{l}t_{p e}(P) \\
(m s)\end{array}$ & $\begin{array}{l}t_{p e}^{*} \\
(m s)\end{array}$ & $\begin{array}{l}t_{r e} / t_{e} \\
(m s)\end{array}$ \\
\hline I & II 5 & 327 & 429 & $24 I$ & 239 & 296 & 86 & - & 127 & 0.35 \\
\hline 2 & IOI & 330 & 392 & 270 & - & 302 & 60 & - & 89 & 0.22 \\
\hline 2 & 80 & 380 & 385 & 300 & 295 & 300 & 80 & - & 92 & 0.26 \\
\hline 4 & 80 & 350 & 374 & 280 & 280 & 282 & 70 & - & 90 & 0.25 \\
\hline 5 & 84 & 330 & 388 & 270 & 270 & 292 & 60 & - & 94 & 0.22 \\
\hline 6 & 64 & 417 & 394 & 336 & 340 & 308 & 81 & - & 87 & 0.24 \\
\hline 7 & 107 & 304 & 382 & 240 & 230 & 283 & 64 & - & 98 & 0.26 \\
\hline 8 & 100 & 366 & 408 & 285 & 290 & 319 & 81 & - & 89 & 0.28 \\
\hline 9 & 113 & 334 & 437 & 255 & 266 & 314 & 79 & - & 121 & 0.30 \\
\hline 10 & 77 & 383 & 416 & 321 & 314 & 326 & 62 & - & 88 & 0.19 \\
\hline I I & 90 & 362 & 406 & 281 & 280 & 298 & $8 I$ & - & 106 & 0.28 \\
\hline 12 & 74 & 237 & 414 & 342 & 350 & 319 & 95 & - & I IO & 0.27 \\
\hline 13 & 90 & 395 & 444 & 300 & 300 & 320 & 95 & - & 122 & 0.31 \\
\hline 14 & 98 & 395 & 448 & 307 & 305 & 333 & 88 & - & II 4 & 0.28 \\
\hline 15 & 82 & 438 & 451 & 324 & 327 & 314 & I I4 & - & 128 & 0.35 \\
\hline 16 & III & 360 & 425 & 260 & - & 312 & 100 & - & 126 & 0.38 \\
\hline 17 & 95 & 380 & 413 & 280 & 280 & 305 & 100 & - & 118 & 0.35 \\
\hline 18 & 75 & 400 & 389 & 300 & 300 & 291 & 100 & - & 107 & 0.33 \\
\hline 19 & 110 & 321 & 402 & 230 & 230 & 276 & 9I & 88 & 124 & 0.39 \\
\hline 20 & 98 & 375 & 412 & 280 & 280 & 310 & 95 & 97 & 102 & 0.33 \\
\hline $2 I$ & 65 & 392 & 382 & 330 & 330 & 304 & 61 & - & 73 & 0.18 \\
\hline 22 & 90 & 400 & 447 & 305 & 305 & 324 & 95 & - & 122 & 0.31 \\
\hline 23 & 86 & 410 & 428 & 330 & 330 & 326 & 80 & 74 & 95 & 0.24 \\
\hline 24 & 97 & 365 & 425 & 310 & 310 & 339 & 55 & 53 & 85 & 0.17 \\
\hline 25 & 97 & 386 & 450 & 280 & 280 & 311 & IIO & 105 & I4I & 0.39 \\
\hline 26 & 95 & 370 & 409 & 290 & 290 & 315 & 80 & 80 & IOI & 0.27 \\
\hline 27 & 90 & 383 & 400 & 270 & 269 & 287 & 113 & II & 126 & $0.4 \mathrm{I}$ \\
\hline 28 & 93 & 385 & 429 & 286 & 287 & 305 & 99 & 98 & 124 & 0.34 \\
\hline 29 & 70 & 407 & 395 & 307 & 303 & 293 & 100 & 103 & 107 & 0.32 \\
\hline 30 & II 4 & 359 & 465 & 277 & 277 & 342 & 82 & 84 & 122 & 0.29 \\
\hline Mean & $9 I$ & 375 & 416 & 290 & 291 & 308 & 85 & 89 & 108 & 0.29 \\
\hline SD & I4 & 33 & 25 & 28 & 28 & I6 & 16 & 17 & I7 & 0.06 \\
\hline$n$ & 30 & 30 & 30 & 30 & 28 & 30 & 30 & Io & 30 & 30 \\
\hline
\end{tabular}

$\mathrm{SD}=$ standard deviation; $n=$ number of measurements. The corrected time intervals for heart rate, age, and sex are marked by an asterisk; the abbreviations are explained in the text.

48 hours before, and during cardiac catheterization in 20 patients. Using the sign test, there was no significant difference in mean heart rate and mean ejection time before and during catheterization; mean total electromechanical systole and preejection time were both slightly, but significantly, prolonged during catheterization. The uncorrected and corrected time intervals as obtained externally during cardiac catheterization are presented in Table 3, together with the internally obtained ejection time and pre-ejection time values. In 2 patients (Cases 2 and 16), in whom the aortic pressure tracing was recorded using a fluid-filled catheter, accurate determination of ejection time was impossible. In the other patients, the externally and internally obtained ejection time were nearly equal, a maximum difference of $1 \mathrm{I} \mathrm{ms}$ being found (Fig. 2). In Io out of 13 patients in whom the left ventricle was catheterized using the catheter-tip manometer, a distinct upstroke point of the pressure tracing allowed exact internal measurement of the pre-ejection time. Fig. 3 shows the pre-ejection time measured externally plotted against the preejection time measured internally. The values are nearly equal; the maximum difference is $6 \mathrm{~ms}$.

The haemodynamic data are given in Table 4 . The cardiac index ranged from 2.9 to $6.5 \mathrm{l} / \mathrm{min}$ per $\mathrm{m}^{2} \mathrm{BSA}$, the peak systolic pressure difference from Io to $110 \mathrm{mmHg}$ ( 1.3 to $14.6 \mathrm{kPa}$ ), and the aortic valve orifice index from 0.42 to $1.83 \mathrm{~cm}^{2}$ per $\mathrm{m}^{2}$ BSA. The peak systolic pressure difference and the aortic valve orifice index are plotted against the corrected time intervals in Fig. 4-6. The patients have been divided according to the criteria of Braunwald and Friedman (1968), i.e. a group with severe stenosis (peak systolic pressure difference 
TABLE 4 Hacmodynamic data

\begin{tabular}{|c|c|c|c|c|c|c|}
\hline Case No. & $\begin{array}{l}\text { Cardiac index } \\
\left(\text { l/min per } m^{2} B S A\right)\end{array}$ & $\begin{array}{l}\text { Stroke index } \\
\left(m l \text { per } m^{2} B S A\right)\end{array}$ & $\begin{array}{l}\text { Left ventricular } \\
\text { pressure } \\
(\mathrm{mmHg})\end{array}$ & $\begin{array}{l}\text { Aortic pressure } \\
\left(m m H_{g}\right)\end{array}$ & $\begin{array}{l}\text { Peak systolic } \\
\text { pressure difference } \\
(\mathrm{mmHg})\end{array}$ & $\begin{array}{l}\text { Aortic valve } \\
\text { orifice index } \\
\left(\mathrm{cm}^{2} \text { per } m^{2}\right. \\
B S A)\end{array}$ \\
\hline I & 3.7 & $4 I$ & $155 / 15$ & I I $5 / 90$ & 40 & 0.70 \\
\hline 2 & 4.2 & 46 & $135 i 10$ & I I נ I & 25 & 0.88 \\
\hline 3 & 35 & 44 & $185 / 20$ & $125 / 90$ & 60 & 0.50 \\
\hline 4 & 4.4 & 49 & $135 / 10$ & $110 / 80$ & 25 & 0.87 \\
\hline 5 & - & - & $165 / 15$ & $115: 85$ & 50 & - \\
\hline 6 & 3.9 & 60 & $175 / 16$ & $105 / 80$ & 70 & 0.62 \\
\hline 7 & 5.1 & 49 & $140 / 15$ & $120 / 80$ & 20 & 1.30 \\
\hline 8 & 6.5 & 67 & $210 / 20$ & $150 / 110$ & 60 & 0.75 \\
\hline 9 & 4.6 & $4^{3}$ & $115 / 15$ & $95 / 75$ & 20 & 1.19 \\
\hline Io & 44 & 54 & $220 / 18$ & I 10/75 & 110 & 0.51 \\
\hline I I & 4.2 & 47 & $150 / 20$ & $100 / 80$ & 50 & 0.70 \\
\hline 12 & 3.5 & 46 & $165 / 22$ & $125 / 85$ & 40 & 0.54 \\
\hline 13 & 2.9 & 35 & I $15 / 17$ & $105 / 80$ & IO & - \\
\hline 14 & 5.0 & 50 & $175 / 14$ & $105 / 80$ & 70 & 0.72 \\
\hline 15 & 3.5 & 45 & $175 / 21$ & $110 / 80$ & 65 & $0.4^{8}$ \\
\hline 16 & $5 \cdot 4$ & 44 & $200 / 15$ & $120 / 95$ & 80 & $0.5^{8}$ \\
\hline 17 & 3.4 & 42 & $200 / 15$ & $135 / 95$ & 65 & 0.54 \\
\hline 18 & 4. I & 55 & $120^{\prime} / 17$ & $110 / 80$ & I0 & - \\
\hline I9 & 4.9 & 44 & $140 / 21$ & $125 / 90$ & 15 & 1.42 \\
\hline 20 & 4.0 & 43 & $150 / 16$ & $110 / 80$ & 40 & 0.67 \\
\hline 21 & 4.3 & 61 & $160 / 20$ & I 10/70 & 50 & 0.82 \\
\hline 22 & 3.7 & 44 & $180 / 20$ & $120 / 83$ & 60 & 0.53 \\
\hline 23 & 3.8 & 49 & $190 / 27$ & I 10 75 & 80 & 0.42 \\
\hline 24 & 4.8 & 55 & $160 / 21$ & $100 / 70$ & 60 & 0.69 \\
\hline 25 & 2.9 & 30 & $145 / 14$ & $115 / 90$ & 30 & 0.53 \\
\hline 26 & 6.2 & 67 & $200 / 24$ & $115 / 80$ & 85 & 0.66 \\
\hline 27 & 4. I & 45 & $125 / 18$ & $115 / 85$ & 10 & 1.83 \\
\hline 28 & 4.2 & 46 & $170 / 17$ & $125 / 95$ & 45 & 0.63 \\
\hline 29 & 4.0 & 60 & $135 / 13$ & $115 / 85$ & 20 & 1.30 \\
\hline 30 & 4.5 & 39 & $145 / 25$ & $120 / 90$ & 25 & 0.78 \\
\hline mean & 4.3 & 48 & $160 / 17$ & $114 / 83$ & 46 & $0.7^{8}$ \\
\hline SD & 0.8 & 8 & $28 / 4$ & $10 / 8$ & 25 & 0.33 \\
\hline$n$ & 29 & 29 & 30 & 30 & 30 & 27 \\
\hline
\end{tabular}

$\mathrm{SD}=$ standard deviation; $n=$ number of measurements.

Conversion factor from Traditional to SI units: $1 \mathrm{mmHg} \approx 0.133 \mathrm{kPa}$.

$>50 \mathrm{mmHg}(6.7 \mathrm{kPa})$ or aortic valve orifice index $<0.70 \mathrm{~cm}^{2}$ per $\mathrm{m}^{2} \mathrm{BSA}$ and a group with mild aortic stenosis (peak systolic pressure difference $\leqslant 50 \mathrm{mmHg}(6.7 \mathrm{kPa})$ or aortic valve orifice index $\geqslant 0.70 \mathrm{~cm}^{2}$ per $\mathrm{m}^{2} \mathrm{BSA}$ ).

Total electromechanical systole was prolonged in I9 out of 30 patients $(63 \%)$ and has a value within the normal range in the other patients. When the total electromechanical systole was plotted against the peak systolic pressure difference and the aortic valve orifice index, a wide scatter was observed (Fig. 4). The ejection time was prolonged in 19 out of 30 patients $(63 \%)$ and was within the normal range in the others. Fig. 5 shows the wide scatter when the ejection time is plotted against the peak systolic pressure difference and the aortic valve orifice index.
In Fig. 6 the pre-ejection time is plotted against the peak systolic pressure difference and the aortic valve orifice index. The pre-ejection time was within the normal range in the majority of the patients. When the ratio of pre-ejection time to ejection time was plotted against the two indices of severity of aortic stenosis, no correlation was observed.

\section{Discussion}

A first condition for the use of externally obtained systolic time intervals in assessing the severity of aortic stenosis is their validity as a measure of the corresponding intervals obtained internally. In normal man a reasonable agreement between externally and internally measured systolic time 

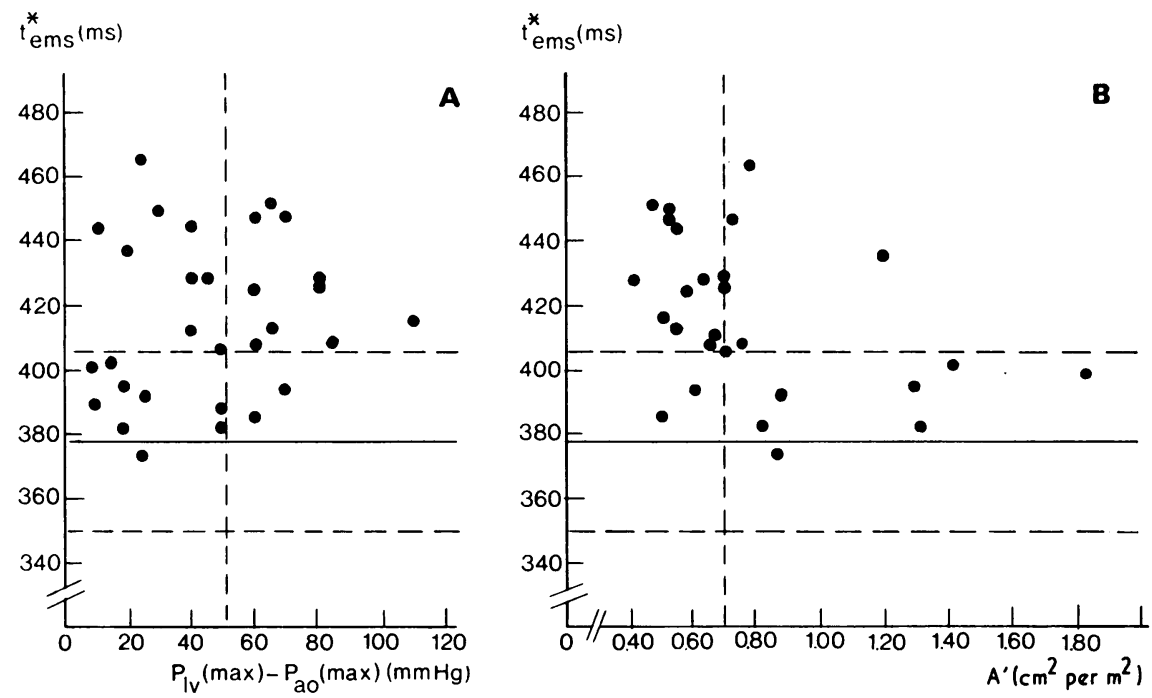

FIG. 4 Relation between the corrected total electromechanical systole $t_{e m s}^{*}$ and $(A)$ the peak systolic pressure difference $P_{l v}(\max )-P_{a o}(\max )$ and $(B)$ the aortic valve area index $A^{\prime}$. The solid line $t_{e m s}^{*}=378 \mathrm{~ms}$ represents the normal value for the corrected total electromechanical systole; the horizontal dotted lines indicate \pm 2 the standard deviations. The vertical dotted lines in $A$ and $B$ divide the patients into a group with severe and a group with mild aortic stenosis.
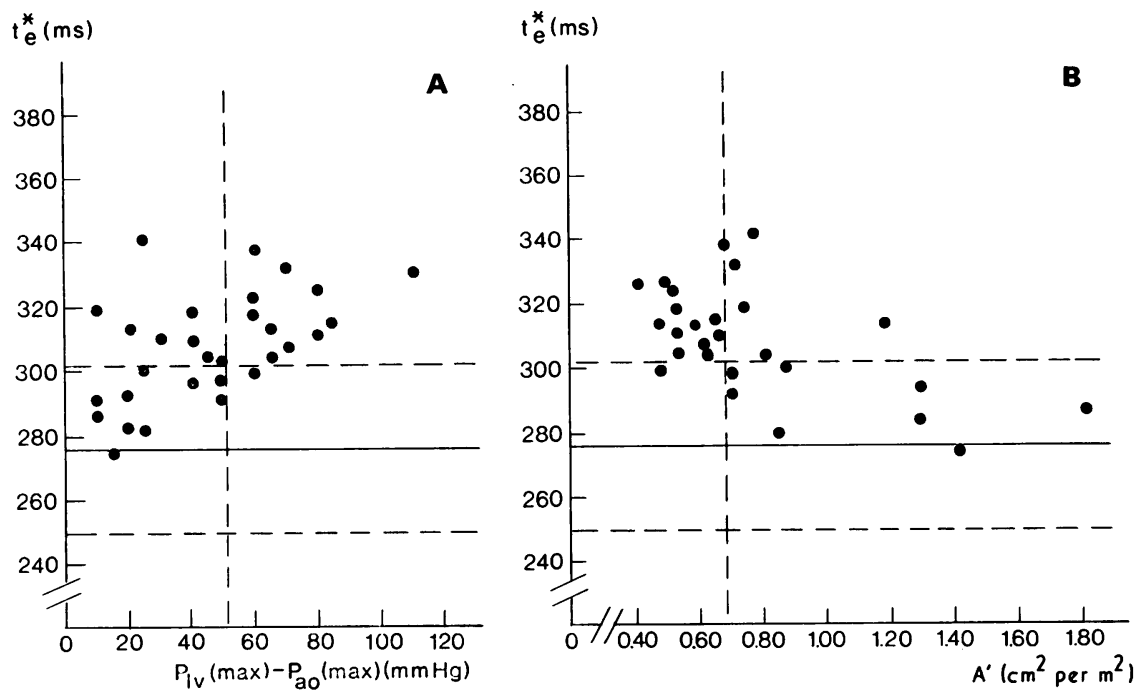

FI G. 5 Relation between the corrected ejection time $t_{e}^{*}$ and $(A)$ the peak systolic pressure difference $P_{l v}(\max )-P_{a o}(\max )$ and $(B)$ the aortic valve area index $A^{\prime}$. The solid line $t_{e}^{*}=277 \mathrm{~ms}$ represents the normal value for the corrected ejection time; the horizontal dotted lines indicate \pm 2 the standard deviations. The vertical dotted lines in $A$ and $B$ divide the patients into a group with severe and a group with mild aortic stenosis. 

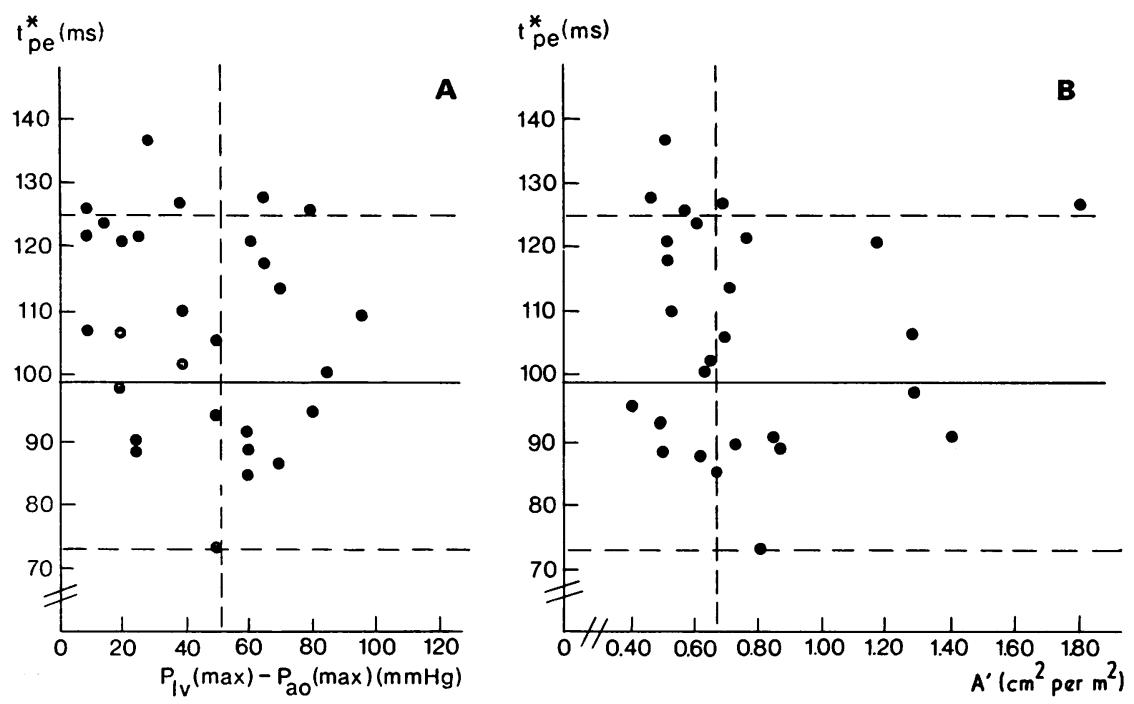

FIG. 6 Relation between the corrected pre-ejection time $t_{p e}^{*}$ and $(A)$ the peak systolic pressure difference $P_{l v}(\max )-P_{a o}(\max )$ and $(B)$ the aortic valve area index $A^{\prime}$. The solid line $t_{p e}^{*}=99$ $m s$ represents the normal value for the corrected pre-ejection time; the horizontal dotted lines indicate \pm 2 standard deviations. The vertical dotted lines in $A$ and $B$ divide the patients into a group with severe and a group with mild aortic stenosis.

intervals has been shown by several authors (Benchimol et al., 1960; Bush et al., 1970; Martin et al., 1971; Fabian, Epstein and Coulshed, 1972; Weissler, 1973). Weissler et al. (1972) have pointed out that patients with aortic stenosis may present certain technical difficulties in measuring systolic time intervals. According to these investigators a clearly discernible aortic second sound can often not be obtained in patients with calcific aortic stenosis, so that total electromechanical systole and pre-ejection time cannot be measured; in addition the carotid arterial pulse may show a poorly delineated incisural notch so that the ejection time cannot be measured. In children, however, calcification of the valve usually does not occur (Braunwald and Friedman, 1968). In the present study the externally obtained tracings allowed time interval measurement in all patients, the absolute values corresponding closely to the same time intervals obtained internally.

Taking the mean value for the whole group, the corrected ejection time was significantly longer than normal, in agreement with other studies (Katz and Feil, 1926; Benchimol et al., 1960; Ježek, 1963; Hartman, 1964; Moskowitz and Wechsler, 1965; Weissler et al., 1972; Bache, Wang, and Jorgensen, 1971). The prolonged ejection time is due primarily to the increased afterload (Shaver et al., 1968). In adult patients with compensated aortic stenosis, a shortened pre-ejection time has been found by a number of investigators (Ježek, 1963; Bonner and Tavel, 1972; Weissler et al., I972; Ibrahim et al., 1973). A shortening of the pre-ejection time, which in fact represents a shortening of the isovolumic contraction time, is caused by a more rapid rise of the intraventricular pressure and/or a diminished end-diastolic pressure difference between the aorta and the left ventricle (Reeve, Kawamata, and Selzer, 1966; Talley, Meyer, and McNay, 1971). In the present study the mean corrected pre-ejection time was within the normal range. This discrepancy cannot be explained by an altered functional state of the heart during catheterization and anaesthesia. Though the pre-ejection time values obtained before catheterization differ significantly from those obtained during catheterization (Table 2), they still fall within the normal range. According to Weissler et al. (1972), the lengthening of the ejection time in aortic stenosis often exceeds the shortening of the pre-ejection time, resulting in a prolonged total electromechanical systole; the ratio of pre-ejection time to ejection time is often strikingly reduced. The mean corrected total electromechanical systole in the present study was prolonged. The ratio of pre-ejection time to ejection time in several of our patients was reduced, as compared with the normal values that can be calculated from the data of Golde and Burstin (1970). 
The relation between systolic time intervals and the severity of aortic stenosis is shown in Fig. 4, 5, and 6 . The best correlation is found between the corrected ejection time and the peak systolic pressure difference $(r=+0.49)$, and between the corrected ejection time and the aortic valve orifice index $(r=-0.55)$. It is obvious from these data that, in children, the severity of aortic stenosis cannot be predicted from the systolic time intervals. At best the results permit the conclusion that a normal corrected ejection time may be construed as strong evidence against a peak systolic pressure difference of more than $50 \mathrm{mmHg}(6.7 \mathrm{kPa})$ or an aortic valve orifice of less than $0.70 \mathrm{~cm}^{2}$ per $\mathrm{m}^{2}$. A prolonged corrected ejection time occurred in mild as well as in severe stenosis. These findings are in agreement with those of other authors who report that carotid artery pulse tracings are less useful in assessing the severity and nature of aortic valve stenosis than in demonstrating the presence of an obstruction (Robinson, 1963; Braunwald et al., 1963).

According to Weissler et al. (1972) left ventricular decompensation may reduce the deviation of systolic time intervals from the normal range found in compensated valve aortic stenosis. Clinical signs of decompensation, however, were absent in all patients studied and the cardiac index was in no case clearly subnormal (Table 4). Though systolic time intervals undoubtedly reflect alterations in left ventricular function, they are of no practical value in assessing severity of aortic stenosis in individual patients. It should be noted that the deviation of the systolic time intervals, as found in the present study and as found by others in various diseases, is often very small, particularly if the deviation is taken as a percentage of the normal value. From this it follows that measurement errors and normal variation in time intervals in an individual patient (Weissler, 1973) may exert a relatively strong influence and have to be taken into account when systolic time intervals are used in assessing cardiac function. Moreover, though the time intervals have been corrected for heart rate, age, and sex, other variables than the severity of aortic stenosis may have had a significant influence on their duration. Correction for variables such as stroke volume and mean aortic pressure, however, is not possible by non-invasive techniques. The presented results indicate that systolic time intervals do not deserve a place among the routine non-invasive methods in evaluating the severity of aortic stenosis. In this respect other non-invasive methods, for instance the electrocardiogram, are far more valuable, though cardiac catheterization still remains the only method for obtaining an accurate assessment of the severity of aortic stenosis.
The authors wish to thank Prof. Dr. W. G. Zijlstra (Department of Chemical Physiology, University of Groningen) for his critical review of the manuscript.

\section{References}

Bache, R. J., Wang, Y., and Jorgensen, C. R. (1971). Hemodynamic effects of exercise in isolated valvular aortic stenosis. Circulation, 44, 1003.

Benchimol, A., Dimond, E. G., and Shen, Y. (1960). Ejection time in aortic stenosis and mitral stenosis. American fournal of Cardiology, 5, 728.

Bonner, A. J., and Tavel, M. E. (1972). Systolic time intervals in congestive heart failure due to aortic stenosis (abstract). Circulation, 45/46, Suppl. II, 133.

Braunwald, E., and Friedman, W. F. (1968). Aortic stenosis. In Paediatric Cardiology, p. 325. Ed. by H. Watson. Lloyd-Luke, London.

Braunwald, E., Roberts, W. C., Goldblatt, A., Aygen, M. M., Rockoff, S. D., and Gilbert, J. W. (1963). Aortic stenosis: physiological, pathological, and clinical concepts. Annals of Internal Medicine, 58, 494.

Bush, C. A., Lewis, R. P., Leighton, R. F., Fontana, M. E., and Weissler, A. M. (1970). Verification of systolic time intervals and the true isovolumic contraction time from the apexcardiogram by micromanometer catheterization of the left ventricle and aorta (abstract). Circulation, 42, Suppl. III, I2I.

Epstein, E. J., and Coulshed, N. (1964). Assessment of aortic stenosis from the external carotid pulse wave. British Heart fournal, 26, 84.

Fabian, J., Epstein, E. J., and Coulshed, N. (1972). Duration of phases of left ventricular systole using indirect methods. I: Normal subjects. British Heart fournal, 34, 874.

Golde, D., and Burstin, L. (1970). Systolic phases of the cardiac cycle in children. Circulation, 42, 1029.

Gorlin, R., and Gorlin, S. G. (1951). Hydraulic formula for calculation of the area of the stenotic mitral valve, other cardiac valves, and central circulatory shunts. American Heart fournal, 41, I.

Hartman, H. (1964). Fonocardiografie en polscurven, in het bijzonder bij aortastenose. Thesis, Leiden.

Ibrahim, M., Silie, M., Delahaye, J. P., and Froment, R. (1973). Systolic time intervals in valvular aortic stenosis and idiopathic hypertrophic subaortic stenosis. British Heart fournal, 35, 276.

Ježek, V. (1963). Clinical value of the polygraphic tracing in the study of the sequence of events during cardiac contraction. Cardiologica, 43, 298.

Katz, L. N., and Feil, H. S. (I926). Clinical observations on the dynamics of ventricular systole. III. Aortic stenosis and aortic insufficiency. Heart, 12, $17 \mathrm{I}$.

Martin, C. E., Shaver, J. A., Thompson, M. E., Reddy, P. S., and Leonard, J. J. (I97I). Direct correlation of external systolic time intervals with internal indices of left ventricular function in man. Circulation, 44, 419.

Moene, R. J. (1974). Systolic time intervals in congenital aortic stenosis. A comparison of simultaneously recorded external and internal indices of left ventricular performance in children. Thesis, Groningen.

Moskowitz, R. L., and Wechsler, B. M. (1965). Left ventricular ejection time in aortic and mitral valve disease. American fournal of Cardiology, 15, 809.

Reeve, R., Kawamata, K., and Selzer, A. (1966). Reliability of vectorcardiography in assessing the severity of congenital aortic stenosis. Circulation, 34, 92.

Robinson, B. (1963). The carotid pulse. I. Diagnosis of aortic stenosis by external recordings. British Heart fournal, 25, $5 \mathrm{I}$. 
Shaver, J. A., Kroetz, F. W., Leonard, J. J., and Paley, H. W. (1968). The effect of steady-state increases in systemic arterial pressure on the duration of left ventricular ejection time. Fournal of Clinical Investigation, 47, 217.

Sherman, J. A., Lewis, R. P., Fontana, M. E., and Weissler, A. M. (I97I). Use of left ventricular ejection time in assessing the severity of aortic stenosis (abstract). Circulation, 43/44, Suppl. II, 225.

Talley, R. C., Meyer, J. F., and McNay, J. L. (197I). Evaluation of the pre-ejection period as an estimate of myocardial contractility in dogs. American fournal of Cardiology, 27, 384.

Ten Hoor, F., and Mook, G. A. (1969). A linear reflection densitometer for indocyanine green. Cardiovascular Research, 3, 373.
Weissler, A. M. (1973). (Ed.) Noninvasive Cardiology. Grune and Stratton, New York and London.

Weissler, A. M., Harris, W. S., and Schoenfeld, C. D. (1968). Systolic time intervals in heart failure in man. Circulation, $37,149$.

Weissler, A. M., Lewis, R. P., and Leighton, R. F. (1972). The systolic time intervals as a measure of left ventricular performance in man. In Progress in Cardiology, p. 155 Ed. by P. N. Yu and J. F. Goodwin. Lea and Febiger, Philadelphia.

Requests for reprints to Dr. Rudolf J. Moene, Department of Pediatric Cardiology, Free University Hospital, De Boelelaan I I 17, Amsterdam, The Netherlands. 